\title{
The Eighth National Radio Exhibition
}

T $T$ is doubtful whether the Radio Exhibition at Olympia is the best occasion for learning what scientific progress is boing made in that particular area of the radio field which is concerned with the reception of broadcast programmes. The exhibition, as exhibition, is admirable, attractive and deservedly popular. But there is no 'radio' to be heard in it.

It might be captious to suggest that 'the show' is really an audio exhibition, but the limiting of demonstration to reproduction of music and spcech distributed at audio (not at radio) frequency does prevent a complete subjective appraisal of the radio receivers shown, since more than half-and a vital half-of the receiver is not in use. Objective appraisal, by the method which the scientific worker regards as normal in other fields, is also impossible, for the reason that on no one of the stands carrying receivers were overall performance curves to bo found on the opening day, and on only one stand were such curves found on the second day of tho exhibition.

An inquiry into the reasons for this almost universal reliance on subjoctive selection-oven when tho absence of facilities for such selection is left out of account - is too extensive for dovelopment here, but it demands attention. It must be admitted that existing knowledge is inadequate for completely objective tosting; it must be inquired what steps are being taken, and by whom, to bridge these gaps in knowledge.

What doos emorge most cloarly from tho study of the new season's receivers, and from their audio frequency performanee, is that the industry has, almost without exception, decided to follow ono of two divergent paths which offer themselves to the designer. One path leads towards the most faithful attainable reproduction of music from tho 'local' broadcasting station, the other towards reproduction of programmes from stations at such distances that fading phenomena, interference between emissions of comparable field intensity, and interference from natural and artificial sources of electrical disturbanco assume dominant importance. The two paths do not diverge rapidly in their early stages, but the ultimate goals aro definitely irreconcilable.

The most marked feature of the audiblo demon. strations is a very notablo and gratifying improvement in the average level of acoustic fidelity. Tho very general introduction of the moving-coil speaker, even in inexpensive sets, and of dual sperkers of the moving-coil typo in the medium and highly priced sets, are milestones common to both paths. The range of frequencies over which the response curve of the speaker system may be taken as flat on the average?, neglecting its very complex fine structure, has been greatly extended. Yet it must be said that no single set which was heard would have deluded an even moderately tolerant musician that he was in the concert room itself. This is said not by way of derogation from the praise due for the very notablo progress made, but to indicate the magnitude of the outstanding scientific and technical problems. The final esthetic aim of broadcasting is not necessurily 'photographic representation', but it is just as necessary that the broadcast receiver should give close acoustic fidelity, as it was necessary that Cezanne and his followers should be as competent draughtsmen as their predecessors.
How far the trend of design has travelled along the alternative path is shown by tho very general provision of 'automatic volume control'. The very great facility for shaping the frequency-acceptance curve which is afforded by the frequency-conversion principle, embodied in tho superheterodyno receiver, has brought such an increase of receivers of this type that this may well be labelled the superheterodyne year. Within the limits set by the international allocation of frequency channels, the suporheterodyne set can probably be mades to give an overall response curve of the same degree of fidelity as the 'straight' set, with greater facility for its displacement to accept either of the alternative 'local' programmes. The old difficulties of high background noise level have boen almost completely surmounted, and so the superheterodyne set is not specifically off the path of high quality local reception.

The autornatic volume control, a devico of high technical ingenuity and surprising practical simplicity for reducing the effects of fading, is, however, in a different eategory. It aims solely at mitigating some of the worst imperfections of emissions which are already foredoomed to æsthetic imperfection. That it makos a great contribution to the vory real pleasures of 'distant listening' is indubitable; that it leads away from the path of highest quality reception is equally indubitable.

Telovision apparatus at tho show brings no surprises, and no great noveltics. Thero is, indeed, a complete cathode-ray television receiver, but it is designed for the present medium-wave thirty-line emissions, for which a cathode-ray receiver is neither necessiary nor woll-suited. The only other modern television receivers shown were both of the mirrordrum type, and both utilised the Kerr effect for light-modulation. Perhaps the one greatest unheralded novelty in the whole exhibition, however, derived its main significance from television requirements. This was the cathode-ray oscillograph with a fluorescent scresn of nine-inch diameter, which was exhibited in the now familiar sealed-off form, requiring accelerating voltages of the samo order as the voltages necessary in the mechanical television receivers already noticed, and thus quite suitable for domestic use.

Next to this particular 'vacuum tube' tho exhibits of highest scientific interest are, probably, other vacuum tubos, such as those which facilitate the application of automatic volume control, the double. diode-triodes, those which improve high-frequency amplification, the sereened pentodes, and those which havo brought the performance of the drybattery driven set to a much higher level, the valves designed for 'class 13 ' and 'quiescent push-pull' amplification.

Special notice must be given to the exceptiorially interesting exhibit by the Post Office, which very properly reminds the visitor that 'radio' and 'broadcasting' are not synonymous. The central feature of the exhibit recalls the fact, alrnady implicit in what has been said above, that the problem of the interference which electrical apparatus-domestic and industrial plant, traction and communication plant, illumination devices and the like-produce in the reception of broadcast programmes is the most important single obstacle to high-quality reception in the great centres of population. 
One last remark is suggested by the ornissions from the exhibition. It is to bo hoped that the Post Office, the British Broadcasting Corporation, and the Radio Manufacturors Association, will not forget that the situation in respect of the highest-quality broadcasting is not yet hopeloss.
'The very qualities which may render the ultrashort wave-bands suitable for television working are tho qualities roquired for very high-quality musical reproduction. Channels should be reserved for services of this character before the existing state of congestion in the medium-wave bands has ostablished itself in these still open bands.

\section{The Welsh Plant Breeding Station, Aberystwyth}

$\mathrm{I}^{\mathrm{N}}$ response to numerous requests, the Welsh Plant Breeding Station, Aberystwyth, has issued a booklet, price 3s., entitled "An Account of the Organisation and Work of the Station from its Foundation in April 1919 to July 1933". 'Tho publication describes in an ominently readablo form tho general principles governing the work of the Station and the lines upon which it is organised and functions. 'Though not intended to be a precise guide to the experiments, it should prove invaluable to visitors and others desirous of a real insight into the general aims underlying the work, the methods employed and the difficulties encountered.

From tho outset, tho policy has been to concentrate all researches on one main problem, namely, grass. land improvement, though this question is necessurily studiod from a number of aspects the chief of which are plant breeding of herbage crops and trials relativo to their seed production, the improvoment and managoment of ordinary farm grasslands and hill grazings, while plant breeding with oats and wheat and invostigations into plant diseases form necessary complements to the central problem.

The breeding of the more important herbage plants, as porennial ryo grass, white clover and cocksfoot, however, is the pivot upon which the work turns as it is by such characters as leafiness, persistence and flowering habit, factors found to be associated with clearly defined types, that the agricultural value of the herbage is determined. Tho safeguarding of truly authenticated stocks, and the best means for their distribution, ure further problems awaiting solution, and the co-operation of the seed trade, farmers' societies and individual farmors has already been enlisted in the latter cause.

In this connexion a plea is put forward for the foundation of somothing in the naturo of a British or Imperial Seed Production Co., which would be a properly conceived and controlled organisation, acceptable alike to the seed trade and the farmer, and competent to produce the right kind of sceds, sufficiently cheaply and adequately authenticated. The far-reaching nature of the term 'managoment' is fully brought out. The importance of the choice of the seeds mixture, tho uso of rotational grazing, and the significance of differences in yield, productivity, carrying capacity and nutritive value of the various types of herbago are discussed in the light of experimontal evidence.

The necessity for ploughing old pasturos prior to re-sowing has entailed a study of the oat plant, as this makes an excellent first crop after grass. Broeding experiments havo been carried out with the view of finding strains particularly suited to theso poor conditions; hardiness and good standing ability being the chief requisites.

Tho work on rough and hill grazings is of particular interest considering the necessity for making the best use of all availablo grassland at the present time. Climate has not been found to be such a limiting factor to the improvernent of hill pastures as had previously been thought, and after a preliminary cultivation by means of a scratching or ploughing operation, a sowing combined with a manurial dressing has proved of immense value. Wild white clover (preferably assisted by inoculation) is the most important species to include in a seeds mix ture for this purpose and, among the grasses, Yorkshire fog and sweet vernal grass have given particularly promising results.

The extent to which the work of the Station has boen helped by the neighbouring county agricultural organisers, landowners and farmors is evidence of the real practical valuo of the investigations being carried on. Tho publication of this booklet cannot fail to increase and widen the interest taken in grassland management as a whole, and in the methods by which our knowledge of the subject is being extended at Aberystwyth in particilar.

\section{The Cape Observatory}

CCIENCE PROGRESS for July contains an

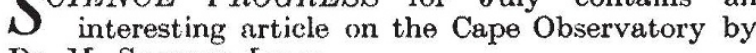
Dr. H. Spencer Jones.

Rev. F. Fallows was tho first director and commenced work in 1821. He worked under great difficultios, the site being inhospitable, the instruments badly made, the assistanco allowed to him hopelessly inadequate; he died in 1831 at the early age of forty-two years. It may be remarked that the amenities of tho site have now been greatly improved, the bare rock having been covered with a good depth of soil, trees planted to shelter the instruments from wind, and a good water-supply laid on.

Henderson was director for only one year, but did good work in that time; inter alia he detected the large parallax of $\alpha$ Centauri.
Maclear was director in 1834-1870. In his early days there ho enjoyed the companionship of Sir J. Horschel, who established an observatory at Feldhausen in order to extend his fathor's survey to tho southern hoavens. Maclear mado an immense number of observations, but their reduction was delayed owing to insufficient staff. It was completed after his rotiroment by his successor, E. J. Stone. Ho in turn was succeeded by Sir David Gill in 1879. Tho great comet of 1882 was tho accidental occasion of detecting the value of photography for determining the position of stars. This led both to the formation of the Cape Photographic Durchmusterung and to the great Astrographic Catalogue of the entiro heavens.

The Capo Zone has been rephotographed under Dr. Spencer Jones, and comparisons of the earlier 